\title{
A EDUCAÇÃO AMBIENTAL COMO FERRAMENTA PARA O DESENVOLVIMENTO INTEGRADO ENTRE CURRÍCULO E FORMAÇÃO DISCIPLINAR
}

\author{
Elisiane Perufo Alles ${ }^{1}$, Elisane Maria Rampelotto \\ ${ }^{1}$ Especialista em Educação Ambiental da Universidade Federal de Santa Maria (UFSM,RS). \\ ${ }^{2}$ Professora e orientadora do curso de especialização pela UFSM. \\ (elisane2007@gmail.com )
}

\section{RESUMO}

Este trabalho de pesquisa foi desenvolvido no Colégio Militar de Santa Maria e busca apresentar de uma forma diferenciada a Educação Ambiental como ferramenta para o desenvolvimento integrado entre currículo e formação disciplinada dos alunos, além de contribuir para a prática profissional a partir da utilização de recursos pouco utilizados. $O$ enfoque aqui proposto é o Google Earth, que através da disponibilidade e analise das imagens pode auxiliar no ensino das questões ambientais, em especial das áreas do Colégio, realizando uma pesquisa exploratória através de uma atividade motivacional, sendo possível analisar e discutir o conteúdo.

Palavras Chaves: Educação Ambiental, Disciplina, Google Earth, Motivação.

\begin{abstract}
Abstrat
This research work was developed in the Colégio Militar de Santa Maria and seeks to introduce a differentiated way environmental education as a tool for integrated development between curriculum and disciplined training of students, in addition to contributing to the professional practice from the use of underutilized features. The approach proposed here is Google Earth, that through the availability and analysis of images can assist in the teaching of environmental issues, in particular case in the areas of the school, performing an exploratory search via a motivational activity, being possible to analyze and discuss the content.
\end{abstract}

Keywords: Environmental Education, Discipline, Google Earth, Motivation.

\section{APRESENTAÇÃO}

Na prática escolar o meio ambiente é estudado de forma dividida, a organização do conhecimento se faz através das disciplinas que abordam sempre os elementos da realidade de forma parcial, resultando numa concepção parcial do mundo e da vida. Este contexto dificulta a formulação de uma proposta geral de ensino, resulta numa mera repetição de conteúdos.

É neste contexto que se elegeu como temática a educação ambiental como ferramenta para o desenvolvimento integrado entre currículo e formação disciplinar, necessidade encontrada a fim de fazer uso dos conhecimentos e recursos tecnológicos disponíveis partindo da necessidade encontrada na instituição de ensino e de um projeto de arborização desenvolvido junto aos alunos 
com participação efetiva dos mesmos e do interesse apresentado em preservar e interagir com o meio em que vivem.

Com o passar dos anos e a repercussão nos dias atuais, aos poucos a sociedade vem se conscientizando de que realmente estamos vivendo uma crise ambiental, a qual põe em risco a sobrevivência de todos que habitam o Planeta Terra. E, para a promoção da consciência ambiental de nossos alunos vejo como ponto de partida a utilização de recursos de multimídia, os quais tornam as aulas mais dinâmicas e participativas, onde ocorra a interação e troca de conhecimentos entre os alunos, professores e entre os mesmo, despertando no educando o espírito corporativo e cooperativo, transformador de nossa sociedade. Cito aqui o Google Earth, o qual é uma ferramenta de visualização geográfica e cartográfica que vem ao encontro das necessidades exploratórias em sala de aula, sendo este software um recurso a ser utilizado na abordagem dos problemas ambientais, e sendo este um software livre, questiono-me porque os professores não o utilizam na sua prática escolar? Como desafio pessoal, optei em conhecer e explorar o Google Earth, a fim de desenvolver este trabalho buscando auxiliar o desenvolvimento integral do aluno interligando currículo e formação disciplinada a educação ambiental e para tal atividade utiliza-se como recurso a localização e mapeamento das áreas degradadas de propriedade do Exército, na região do Colégio Militar de Santa Maria.

Como objetivos específicos este trabalho busca:

- Identificar e reconhecer áreas degradadas;

- Localizar nascentes em imagens do Google Earth;

- Ensinar técnicas básicas de recuperação de nascentes;

- Aplicar medidas compensatórias em áreas degradadas;

- Realizar atividades práticas (oficinas) e

- Avaliar as atividades desenvolvidas.

A educação ambiental deve ser trabalhada de forma interdisciplinar, onde todas as disciplinas utilizem dos recursos e conhecimentos a fim de interligar os fenômenos da natureza, passando para o aluno a visão e idéia de sistema ${ }^{1}$.

\section{O USO DO SISTEMA DE INFORMAÇÃO NO AMBIENTE ESCOLAR}

A visão de um mundo real pela internet, mais precisamente as imagens postas pelo Google Earth, mostram realidade do que hoje encontramos de transformações ambientais provocadas pelo homem.

O Google Earth é um software desenvolvido e distribuído pela empresa americana Google cuja função é apresentar um modelo tridimensional do globo terrestre, construído a partir de mosaico de imagens de satélite e de fontes diversas, entre estas, imagens aéreas (fotografadas de aeronaves) e GIS 3D (Serviço de Informação Geográfica). Todo este recurso permite ao usuário, que com um simples clique no mouse, possa "viajar" para qualquer parte do mundo e apreciar as fantásticas paisagens terrestres. $O$ programa pode ser usado simplesmente como um gerador de mapas bidimensionais e imagens de satélite ou como um simulador das diversas paisagens presentes no Planeta Terra. Com isso, é possível identificar lugares, construções, cidades, paisagens, entre outros elementos, servindo como ferramenta

\footnotetext{
${ }^{1}$ Um sistema é um conjunto de partes interdependentes que atuam visando a um objetivo comum. http://cascavel.ufsm.br/revistas/ojs-2.2.2/index.php/remoa
} 
geográfica ambiental de apoio na educação ao aluno em sua formação de conhecimento e desenvolvimento moral, social, cultural e econômico.

Hoje, a educação não está baseada somente na escrita e na oralidade, pois com o avanço das tecnologias, chama mais atenção no aprendizado que a simples transferência do conhecimento do professor em sala de aula. Na percepção de Pierre Lévy (1993) “o conhecimento deveria ser apresentado de três formas: oral, escrita e a digital. Embora as três formas coexistam, torna-se essencial que a era digital vem se apresentando com uma significativa velocidade de comunicação". Continua ainda este raciocínio os autores Moran, Masetto e Behrens (2003) que não deve ser mistificado o uso discriminado de computadores em salas de aula, sendo que o uso deste equipamento pode vir a contribuir para uma nova formação metodológica de aprendizado. Ainda neste contesto Moran (1997) acrescenta que o uso das técnicas de informatização vem contribuir para as diversas aplicações educacionais, para a pesquisa, educação a distancia (o que vem se propagando com os novos paradigmas da educação quer seja para formação de graduação superior, ou até mesmo cursos de aperfeiçoamento, entre tantos outros casos, eliminando desta forma a distância geográfica entre o aluno e o professor).

O processo de apreensão de conhecimento por intermédio da informatização não é tão novo quanto possa parecer, visto que tem como principal fator o princípio da visualização, o que há anos na história vem se desenvolvendo, só que na era digital vem se adotando mais ao cotidiano.

O uso do Google Earth é a ferramenta de aprendizado escolhido para estudo, pois é um programa que desenvolve a curiosidade de conhecer novos lugares sem precisar sair de casa ou da sala de aula. Sem dúvida o Google Earth é o programa que desenvolve a visualização geográfica e cartográfica, pois a visualização das imagens se dá via satélite o que especializa as questões de fronteiras (limites políticos), questões ambientais, sociais e culturais, e a própria história da humanidade.

Qualquer que seja área de estudo a ser desenvolvida pelo educador, o sistema de informatização é meio adequado como complemento da atividade de aprendizado, desde que o professor saiba desenvolver esta atividade, atuando como codificador deste recurso, fazendo despertar o interesse pela mídia usada.

O estudo do meio ambiente através destas imagens vem colaborar para estudo da degradação do meio ambiente pela ação antrópica do homem, na área urbana e rural. A visualização geográfica espacial da terra dá uma noção ao aluno das conseqüências do crescimento desordenado das cidades, da questão econômica e cultural que o homem vem desenvolvendo através dos tempos.

A questão da promoção da consciência ambiental que se procura desenvolver através do aprendizado em sala de aula tem como principal objetivo de orientar o aluno o que seja uma erosão, uma nascente, um rio, uma floresta, um campo, etc. Junto com este material de aprendizado mais o conceito teórico, juntamente do que a Lei ambiental dispõe para preservação do meio ambiente, o aluno vai passar a ter uma visão critica e construtiva para o seu aprendizado.

Levando-se em conta que os estudos quanto às defesas da União está relacionada diretamente às forças armadas, busca-se a partir da educação básica do sistema educacional dos colégios militares, disponibilizar tal conhecimento e familiaridade ao aprendizado de nossos alunos, partindo do reconhecimento das imagens do Google Eahrt e uso adequado do mesmo na preservação e da área entorno do estabelecimento de estudo, ou seja, do Colégio Militar de Santa Maria, RS. 
Como instrumento desta pesquisa, foi utilizado o diário de campo o qual é uma ferramenta pedagógica que expressa uma das formas de avaliação do aluno no sentido de aferir suas habilidades de: descrever, relatar, refletir e propor, além de ser uma fonte de informações que, sistematizadas, poderão originar material para construção de relatórios, trabalhos de conclusão de curso, artigos, projetos e serviços.

O trabalho foi desenvolvido no colégio militar com estudantes do sexto ano do ensino fundamental de uma turma de 28 alunos, sendo utilizado para a pesquisa apenas 10 deles.

Realizado no laboratório de informática onde os alunos tiveram acesso à rede de multimídia de visualização geográfica baseada em imagens de satélites desenvolvendo a atividade proposta por este trabalho.

O ensino se deu com a explanação dos conceitos referentes ao meio ambiente, e os conhecimentos prévios dos alunos, seguidos da utilização e exploração das ferramentas existentes na internet.

A utilização das imagens do Google Eart sobre a questão ambiental em torno do colégio foram analisadas e debatidas entre os alunos, sobre quais as conseqüências futuras que poderão ocorrer naquela região se não houver uma preservação e uma recomposição das áreas afetadas pela ação antóprica do homem.

Uma das temáticas interessantes que foi desenvolvida nesta pesquisa, no ensino do ambiente utilizando a visualização do Google Earth é a questão de processos erosivos, uma das questões presente no ambiente de estudo em questão onde estas áreas, geralmente, são identificáveis aos nossos olhos por estarem em cor creme clara (figura 1). Na sala de aula pode-se trabalhar a temática da erosão fazendo indagações como: o que você entende por erosão? Qual motivo ou atividade faz com que o ser humano chegue a erodir áreas de solo? Qual seria a conseqüência desta erosão para esta população que reside próximo? Entre outras questões.

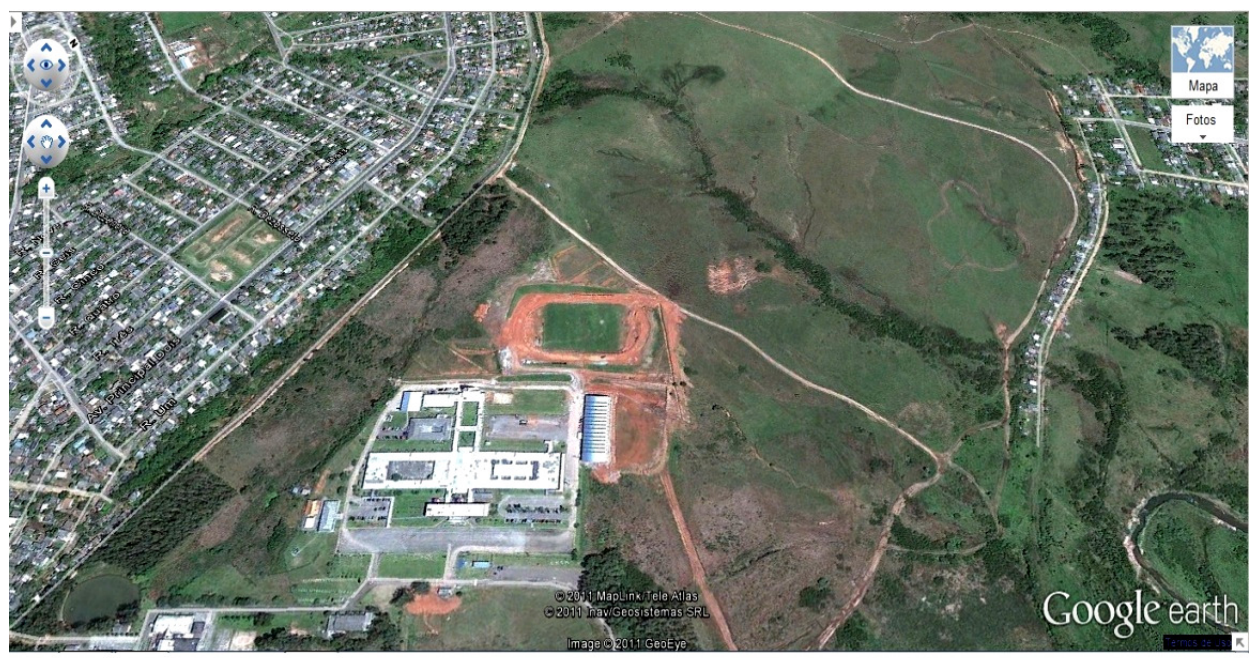

Figura 1. Visualização aérea da área do Colégio Militar de Santa Maria.

Fonte: Google Earth (2011).

É possível observar que muitos alunos não têm a ideia das implicações ambientais das áreas em processos erosivos. Com a visualização vertical ${ }^{2}$ (como mostra a figura 1) e a explicação

\footnotetext{
${ }^{2}$ Há duas formas de se visualizar as imagens de satélite do Google Earth: de forma perpendicular (visualização vertical), e de lado (visualização oblíqua). O usuário escolhe conforme desejar.
} 
contínua e interativa do professor com o aluno ocorre uma compreensão desta ideia, materializando a compreensão do espaço geográfico.

Durante a realização das atividades foi notória a participação geral, pois os alunos demonstram facilidade em se envolver com o assunto abordado, remetendo assim a um contexto educativo produtivo de trocas e assimilações significativas, tudo é abordado em um clima de indagações colocando-os como centro do desenrolar pedagógico.

Como recurso na apresentação dos resultados, os alunos serão classificados em A referente ao aluno 1 (um), B referente ao aluno 2 (dois), C referente ao aluno 3 (três) e assim sucessivamente nas ordens alfabética e numérica.

Durante o uso do Google Earth no laboratório de informática, observou-se a atenção dos alunos sobre a questão ambiental, visto que os mesmos já estavam interados do assunto por já terem desenvolvido junto ao sexto ano o trabalho interdisciplinar com a temática sobre o assunto meio ambiente.

Muitos dos alunos se surpreenderam com o poder de visualização das imagens no processo de ensino/aprendizagem do ambiente, onde para alguns este era um recurso novo e até então desconhecido. Como relatou o aluno B que um amigo havia lhe dito que o bairro Itararé não aparecia. Além de pedirem como o aluno F para visar o morro das antenas.

Após as explanações dos conceitos básicos e definições usuais de importância para a atividade e as considerações dos alunos, foi mostrada a imagem vertical, perpendicular de cima para baixo, do CMSM e a identificação e reconhecimento do local, seguido da aproximação e ate mesmo da visão obliqua das áreas abordadas, sendo os alunos questionados sobre o que achavam ou entendiam das imagens. $O$ aluno $F$ foi o único que conseguiu identificar as nascentes. A partir de conversas informais com o aluno em questão foi possível verificar que o mesmo apresenta um grande interesse no assunto e o busca constantemente para o seu aprendizado, demonstrando ser um aluno curioso e investigativo. As demais respostas se referiam a vegetação, rio, monte de terra, rochas e mata ciliar.

Durante a abordagem das nascentes foi possível perceber uma grande dificuldade dos alunos sobre o assunto. O maior questionamento referente ao assunto foi o como aquelas nascentes secaram e se, ao realizar o reflorestamento da área, voltará a ser um rio. Já quanto ao assunto "Erosão" os alunos possuíam mais conhecimento. Para o aluno A, a erosão é decorrente ao desmatamento. Já o aluno $\mathrm{C}$ acredita que a erosão que aparecia na imagem era decorrente da ampliação do colégio. Alguns alunos que acharam que a imagem representava um monte de terra ou entulho da construção.

Ainda referente as respostas, alguns alunos abordaram, dentre eles o aluno D, que as imagens vistas referente à degradação era resultado dos incêndios. Vale ressaltar que estes são bens comuns em torno do colégio.

Ao serem questionados sobre as soluções para a conservação e manutenção do ambiente, todos os alunos relataram a questão de realizar o plantio de árvores entorno das nascentes e nas áreas desmatadas. $\mathrm{O}$ aluno $\mathrm{D}$ ressaltou a importância de não realizar as queimadas. $\mathrm{O}$ aluno $\mathrm{E}$ abordou a questão das empresas investirem na área, para realizar o reflorestamento, além de fazer uma parceria com a prefeitura, diz o aluno $D$.

É possível perceber o envolvimento e entendimento dos alunos referente ao meio ambiente. Mas o que destaco neste trabalho foi a consideração do aluno $F$ que relatou que não é possível realizar a conscientização só dentro da escola, que este trabalho teria que ser feito com as grandes empresas, por meio de folhetos ou cartaz, para que todos fosse conscientizados. Referente a esta colocação foi comentado que a promoção da consciência ambiental se dá por 
meio da escola visto que os alunos serão os agentes ativos na preservação e divulgação. Ao chegarem em casa os mesmos irão conversar com seus pais, amigos, familiares, colegas sobre o que aprenderam e mais ainda irão intervir/corrigir quando perceber algo errado em nosso meio.

\section{CONCLUSÃO}

Considerando a atual informatização das escolas (às vezes lenta por motivos econômicos, político ou estrutural) a forma como foi desenvolvida esta pesquisa pode aperfeiçoar o uso de novas ferramentas de informação pelos professores. Com certeza, esta prática traz uma nova perspectiva de "pensar o ensino do ambiente", além da importância do conhecimento construído com os alunos de forma coletiva.

Observou-se também que as mídias eletrônicas interativas apresentam uma potencialidade da junção da ferramenta, do ensino e da temática de forma que, não só os conteúdos ambientais, como os demais conteúdos ligados ao espaço geográfico, tendem a diversificar as práticas pedagógicas e fazem com que as aulas sejam mais interessantes para os alunos e otimizado no processo ensino-aprendizagem, desta forma desenvolvendo um trabalho ativo e motivador junto ao educando.

Frente a uma postura conjunta com o trabalho que está sendo desenvolvido, acredito que se faz necessário dar continuidade ao presente projeto, tendo em mente a inovação e a qualidade de melhoria da prática, pois intervindo de forma mediadora e conectiva tentei aliar a minha proposta ao ritmo de trabalho já estabelecido pelos alunos, acreditando ser esta a forma adequada sem agredir o aluno com a mudança.

Ainda temos muito a mudar e trabalhar para a melhoria do nosso ambiente, com esta proposta foi possível, apresentar conceitos, reconhecer, manipular e explorar o Google Earth, podendo, juntamente com os alunos, identificar as áreas degradadas e nascentes da área do colégio militar procurando soluções para a tal problemática e ensinando técnicas de recuperação. Vejo que não foram todos os objetivos alcançados, pois podemos realizar oficinas e colocar em pratica todo o conhecimento adquirido, além de explorar mais a ferramenta de visualização geográfica a qual possui muitos recursos não explorados nesta pesquisa.

Durante estes momentos de integração com a realidade a qual desenvolvi a minha proposta final, percebi que, como já havia mencionado, o interesse das crianças é voltado para assuntos diversos, porém, o que se destaca, é que muitos ainda não se vêem como agentes transformadores na promoção da conscientização e preservação do meio ambiente.

Explorar as ferramentas da internet é um recurso ainda pouco explorado por nós professores e muito motivacional aos alunos, contudo é visto que o aluno dentro destas condições interage com maior facilidade e receptividade auxiliando desta forma no seu aprendizado. 


\section{REFERÊNCIAS}

BRASIL, Lei 9394/96 de 20/12/96 -- Lei de Diretrizes e Bases da Educação Nacional. Brasília (DF): Diário Oficial da União, $n^{\circ} 248$ de 23/12/1996.

COLEGIO MILITAR DE SANTA MARIA. Proposta pedagógica <www.colegiodovagao.com.brl> Acesso 12 de Outubro 2011.

GOOGLE EARTH. A 3D interface to the planet Apresenta o programa interativo do Google Earth. Disponível em < http://earth.google.com/>. Acesso: em 10 de setembro de 2011.

CRUZ, Cláudio. Diário de campo: fundamental instrumento de avaliação para supervisão em estágio profissional. In: Cadernos de Textos de Serviço Social. V.4, n⒌ Belém/PA: UNAMA, out/1998;

LAKATOS, Eva Maria. MARCONI, Marina de Andrade. Fundamentos de metodologia cientifica. São Paulo:Editora Atlas, 1990.

LÉVY, Pierre. As tecnologias das inteligências: o futuro do pensamento na era da informática. Rio de Janeiro: Editora 34, 1993.

MORAN, José Manuel. Como utilizar a internet. Ci. Inf, Maio/Ago. 1997, vol. 26, No 2.

MORAN, José Manuel, MASETTO, Marcos \& BEHRENS, Marilda. Novas tecnologias e mediação pedagógica. 7a ed. São Paulo: Papirus, 2003.

NEGRINE, Airton. Aprendizagem e desenvolvimento infantil. POA: PRODIL, 1994

NEGRINE, Sofia L. (Org.) Gestão da escola desafios a enfrentar. RJ:DP\&A, 2002

RAMOS, C. da S. Visualização cartográfica e cartografia multimídia. São Paulo: Unesp, 2005, 184p.

RAMOS, Cristhiane da Silva; GERARDI, Lúcia Helena de Oliveira. Cartografia Interativa e Multimídia:

Situação Atual e Perspectivas. In: GERARDI, L. H. de O.; MENDES. I. (org.). Do Natural do Social e de suas interações: visões geográficas. Rio Claro; PPGGEOUNESP/ AGETEO, 2002. p.239-247. 